\title{
Collaboration with the first world can be fruitful
}

Dr P. T. Haskell, Director of the Centre for Overseas Pest Research (COPR), London, argues for close cooperation in science between the developing and industrialised world.

THE article on research in third world countries (2 March, page 8 ) presents a gloomy picture of non-cooperation between industrialised and developing countries. But the charges it reports of "scientific colonialism" may be more misleading than helpful.

Of course "scientific colonialism" occurs, but there is no evidence to show that it is widespread in first/third world projects. Much depends on the presentation of the objectives of the work so for countries to claim that first world researchers exploit "lax safety and health regulations" is meaningless unless actual cases are cited. My laboratory has projects in several developing countries on the long term environmental effects of insecticides and this work has, in some instances, necessitated the application of DDT, an insecticide now banned in most of the first world. Should I therefore be accused of "colonialism" or of "exploiting lax safety regulations" by providing developing countries with information on this compound relevant to the improvement of their agriculture and public health?

Similarly the unqualified statement that "third world scientists involved are left untrained ... and the visiting team . . . takes its data with it" is simply untrue in a large number of cases for which I can give chapter and verse. Again, although I agree that it has occurred, evidence is required on the nature and extent to support such a sweeping generalisation and to clarify the root causes. Nowadays research contracts with developing countries usually contain clauses about publication of results and retention of data. One of the problems, however, is that developing countries often do not possess the facilities or resources to store or use large bodies of data; unless some special arrangement is made this is lost to science and may result in the later duplication of work.

The claim that because of funding pressure "the North is making a de facto determination of the science policy of the South" needs to be looked at more critically. There have been many cases of the attempted transfer of inappropriate western technology into developing countries. The main reason for this, however, is not funding pressure, but the cultural gap between scientists and science policy administrators in both the industralised and developing countries.

There is certainly considerable scientific arrogance in the first world about the value of its scientific solutions, often joined to ignorance about the relevance of developing country practice. This has been nowhere more apparent than in agricultural development, where, for example, only relatively recently has there been recognition of the virtues of traditional peasant agricultural systems and the need to conserve certain aspects of them and support them with appropriate modern technology. To do this, however, needs considerable effort to increase communication between, in this example, farmers and scientists, and it is often the lack of this basic exchange of ideas which impedes and corrodes the relationship between first and third world science.

Let me now turn to the contention that one of the objectives of research collaboration is to seduce the best brains from developing countries to work in and for the first world. The implication is that interchange of scientists should be stopped. This certainly runs contrary to the views expressed to me on many occasions in developing countries that one of the best positive aspects of first/third world science collaboration is the training and experience which developing-country scientists can derive from a spell of work in an industrialised country.

It is a fact that a proportion of such visitors stay and take up employment; but what are the reasons for this? In every case known to me there are two important ones. The first is that the scientist is in a field where the facilities available in his home country simply do not allow him to conduct the research he wants to carry out. The second is economic: at home there are no jobs or the rate of pay is too low. The latter is important. It concerns science policy in that support for research and the necessary institutions often has a low priority in many developing countries.

I was closely concerned for many years with the (UNDP/FAO) Desert Locust Project. During the course of the project more than a hundred developing country scientists were given advanced training. A survey carried out at the end of the project showed that less than a third of those trained were working at the job for which they were trained. Many had gone to commercial companies because of better pay; several found their training allowed them to apply for jobs as science administrators in departments other than the one which requested the original training; others discovered that there were simply no posts in their discipline in government service. It could be argued that this represents a loss of talent in a particular sphere of science in the developing countries concerned; or it could be argued that the total country stock of scientists of a particular level had been increased. The difficulty is to decide what disposition of these scientists will give maximum benefit to their home country-and that is a matter for the science policy of that country.

The last point I want to comment on is the very curious claim that the transfer of expertise can at best be partial because a large proportion of the research findings of the first world are military or industrial secrets. I'm quite sure that the late Dr Schumacher would have pointed out that most of this technology is quite inappropriate and indeed irrelevant to developing country needs.

\section{The real problem is application}

The real problem has nothing to do with shortage of research results, but the fact that they are not applied. In my own field of crop protection I get tired of pointing out that the application of presently available and published technology to small-farmer food-crop production in developing countries could quickly result in increased yields of at least $5-10 \%$, and more in the long term-probably enough to eliminate malnutrition in large areas of the world. The use of first world research in developing countries almost always demands local research and development, but this essential requirement is often overlooked by both parties and is one of the greatest obstacles to the transfer of technology and expertise. A successful transfer must take into account not only the scientific and technical requirements but the socio-economic and cultural background as well where most of the difficulties arise.

I should not like it to be thought from the foregoing that I consider all is well with research cooperation arrangements between the first and third worlds, but it will not be improved by a one sided presentation of the issues. There is much scope for information gathering and if the Pugwash group can help develop that then it will be doing all of us a service. I say "all of us" deliberately: one of the main difficulties in this area is the paternalistic attitude of much of western science towards its developing country counterpart, and the feeling this engenders that we have nothing to learn from them. This is not only nonsense-it is unscientific. 